\title{
Resposta da aveia preta (Avena strigosa Schreb) à irrigação por aspersão e adubação nitrogenada
}

\author{
Pedro Henrique de Cerqueira Luz ${ }^{1^{*}}$, Valdo Rodrigues Herling ${ }^{1}$, Gustavo José Braga ${ }^{2}$, José \\ Carlos Machado Nogueira Filho ${ }^{1}$, Letícia de Abreu Faria ${ }^{1}$, César Gonçalves de Lima ${ }^{3}$
}

${ }^{1}$ Departamento de Zootecnia, Universidade de São Paulo, Rua Duque de Caxias, 225, Cx. Postal 23, 13635-900, Pirassununga, São Paulo, Brasil. ${ }^{2}$ Departamento de Descentralização do Desenvolvimento, Agência Paulista de Tecnologia dos Agronegócios, Brotas, São Paulo, Brasil. ${ }^{3}$ Departamento de Ciências Básicas, Faculdade de Zootecnia e Engenharia de Alimentos, Universidade de São Paulo, Pirassununga, São Paulo, Brasil. *Autor para correspondência.E-mail: phcerluz@usp.br

\begin{abstract}
RESUMO. O objetivo do estudo foi avaliar os efeitos da adubação nitrogenada e da irrigação por aspersão no crescimento e na produção de massa seca (MS) da aveia preta (Avena strigosa Schreb). Foram avaliadas quatro doses de nitrogênio $(0,50,100$ e $150 \mathrm{~kg}$ de $\mathrm{N} \mathrm{ha}^{-1}$ ) e, também, a presença ou ausência de irrigação. Foram determinadas as seguintes variáveis: altura de planta, produção de massa seca, taxa de crescimento e o teor de MS. Quando irrigada, a altura da planta foi maior, refletindo maior produção de massa seca. Na área de sequeiro, o teor de MS foi superior (24,7\%) ao da área irrigada (18,7\%). Quanto à adubação nitrogenada, houve resposta somente para altura de planta, com comportamento linear, quando da utilização de irrigação. Os efeitos da irrigação foram mais determinantes para a produção da aveia preta que a adubação nitrogenada.

Palavras-chave: altura de planta, nitrogênio, produção de massa seca.
\end{abstract}

\begin{abstract}
Response of black oats (Avena strigosa Schreb) on the aspersion irrigation and nitrogen fertilization. The objective of the study was assessing the effect of the nitrogen and the aspersion irrigation on the growth and dry matter yield of black oats (Avena strigosa Schreb). The experiment was conducted in the Campus of USP in Pirassununga, São Paulo State. In the study were evaluated four nitrogen levels $(0,50,100$ and $150 \mathrm{~kg}$ of $\mathrm{N} \mathrm{ha}^{-1}$ ) and also the presence or absence of the irrigation. The plant variables evaluated were: mean height, dry matter percentage, yield and growth rate. The results had disclosed to greater height of plant in the irrigated condition, reflecting in the higher production of dry matter. In dry land area, percentage of DM was $24.7 \%$ and in irrigated area $18.7 \%$. The nitrogen was significantly only for plant mean height that showed linear fit when carried through the irrigation. The effect of the irrigation was better for the production of black oats than nitrogen.
\end{abstract}

Key words: height of plant, nitrogen, dry matter yield.

\section{Introdução}

Em razão do déficit hídrico que se observa no Sudeste e Centro-oeste brasileiro entre os meses de maio e outubro, a produção de forragem apresenta decréscimo considerável, reduzindo, assim, a oferta de alimento aos animais. A utilização de plantas forrageiras de inverno, associada ao uso da irrigação, surge como alternativa de solução para este problema e uma das opções de cultivo para essa época do ano é a aveia, planta de clima temperado que apresenta boa adaptação às baixas temperaturas (Floss, 1988).

As espécies de aveia podem ser destinadas à produção de grãos ou de forragem. A aveia preta (Avena strigosa Schreb) é utilizada como planta forrageira, pois apresenta alta produção de massa seca e possui resistência à ferrugem, no entanto, seus grãos não apresentam valor comercial. A aveia branca (Avena sativa L.) e a amarela (Avena byzantina C. Koch) são indicadas para a produção de grãos e também são usadas como plantas forrageiras (Godoy et al., 1990; Flaresso e Almeida, 1992).

Reis et al. (1993a) verificaram acréscimos significativos na produção de massa seca com o aumento da idade ao primeiro corte, num estudo em Jaboticabal, Estado de São Paulo, obtendo, para a aveia preta, produções de $1.751 \mathrm{~kg} \mathrm{ha}^{-1}$, aos 60 dias, e $3.983 \mathrm{~kg} \mathrm{ha}^{-1}$, aos 74 dias. Reis et al. (1993b), nas mesmas condições de solo e clima do estudo anterior; testaram três épocas de plantio para a aveia preta e três cultivares de aveia amarela (UPF2, UPF3 e UPF7). Pelos resultados obtidos, a aveia preta teve o melhor desempenho quanto à produção de massa 
seca. O plantio, no início de abril, resultou em melhores produções de massa seca, alcançando o total de $5.747 \mathrm{~kg} \mathrm{ha}^{-1}$, contra os $3.463 \mathrm{~kg} \mathrm{ha}^{-1}$ para o plantio tardio.

Alvim et al. (1994) avaliaram, na Zona da Mata de Minas Gerais, estudo com aveia amarela, com o objetivo de testar dois fatores, sendo um deles a época de semeadura e o outro a freqüência da lâmina de irrigação $(20 \mathrm{~mm})$. Os resultados para as épocas de semeadura indicaram condições mais favoráveis para aquelas realizadas precocemente. As maiores freqüências de irrigação levaram a acréscimos acentuados na produção de massa seca, a partir de 21 dias. A produção total da primeira época para o tratamento sem irrigação foi de $3.893 \mathrm{~kg} \mathrm{MS}$, enquanto que a irrigada a cada sete dias foi de 6.355 $\mathrm{kg} \mathrm{MS} \mathrm{ha-1}$. Neste estudo, os autores determinaram a altura das plantas por ocasião do corte, e os resultados apontaram maiores alturas para a primeira época de plantio, e entre cortes para o segundo. Quanto à irrigação, foram observadas maiores alturas para os tratamentos de maior freqüência.

Ferreira (1988) estudou os efeitos da irrigação na produção de aveia preta, em Viçosa, estado de Minas Gerais, variando as lâminas de irrigação em função da evaporação do tanque classe "A" $(60,70,80$ e $90 \%$ ), com turno fixo de irrigação de cinco dias. O tratamento com irrigação, correspondente a $60 \%$ da evaporação do tanque classe "A", proporcionou o melhor resultado, atingindo $3.993 \mathrm{~kg} \mathrm{MS} \mathrm{ha}^{-1}$, para a idade de corte de 53 dias, com altura de planta de 60 $\mathrm{cm}$. Aliando os aspectos da adubação nitrogenada e das lâminas de irrigação, Teodoro (1991) conduziu um estudo com a cultivar UPF7 de aveia amarela, em Pirassununga, Estado de São Paulo, testando quatro lâminas de irrigação $(0,50,100$ e $150 \%$ da evaporação do tanque classe "A"- ECA) e quatro doses de $\mathrm{N}\left(0,80,160\right.$ e $240 \mathrm{~kg}$ de $\left.\mathrm{N} \mathrm{ha}{ }^{-1}\right)$. A produção de MS apresentou tendências de melhores resultados para $100 \%$ da ECA e $160 \mathrm{~kg}$ de $\mathrm{N} \mathrm{ha}^{-1}$, seguido pelo tratamento com $50 \%$ ECA e $80 \mathrm{~kg}$ de $\mathrm{N} \mathrm{ha}^{-1}$, tendo efeito quadrático tanto para a irrigação quanto para a adubação. No entanto, na condição não-irrigada não se encontrou resposta para o nitrogênio.

Em função desses aspectos, o objetivo do trabalho foi verificar os efeitos da adubação nitrogenada e da irrigação no cultivo da aveia preta.

\section{Material e métodos}

O experimento foi conduzido no Departamento de Zootecnia da Faculdade de Zootecnia e Engenharia de Alimentos, no Campus da USP, em Pirassununga, Estado de São Paulo, situado a 21 ${ }^{\circ} 59^{\prime}$ de latitude sul e $47^{\circ} 26^{\prime}$ de longitude oeste. O solo é classificado como Latossolo Vermelho distrófico típico e o clima, segundo Kooepen, do tipo Cwa, mesotérmico de inverno seco e verão quente e chuvoso. Os atributos físicos e químicos do solo, para a camada de 0 a $20 \mathrm{~cm}$ de profundidade, encontram-se na Tabela 1 .

Tabela 1. Análise física e química do solo $(0-20 \mathrm{~cm})$.

\begin{tabular}{|c|c|c|c|c|c|c|c|c|c|}
\hline \multicolumn{10}{|c|}{ Análise química } \\
\hline$\overline{\mathrm{pH}}$ & M.O. & $\mathrm{P}$ & $\mathrm{K}$ & $\mathrm{Ca}$ & $\mathrm{Mg}$ & $\mathrm{H}+\mathrm{Al}$ & SB & $\mathrm{T}$ & $\mathrm{V}$ \\
\hline $\mathrm{CaCl}_{2}$ & $\% \quad 1$ & $\mathrm{Mgdm}^{-3}$ & \multicolumn{6}{|c|}{$\mathrm{mmol}_{c} \mathrm{dm}^{-3}$} & $\%$ \\
\hline 4,8 & 3,3 & 10 & 1,1 & 18,0 & 11,0 & 47 & 30 & 77 & 39 \\
\hline \multicolumn{10}{|c|}{ Análise fisica } \\
\hline \multicolumn{3}{|c|}{ Granulometria \% } & \multicolumn{3}{|c|}{ Densidade global } & \multicolumn{2}{|c|}{ Umidade $\mathrm{gg}^{-1}$} & & Infiltração \\
\hline Areia & Silte & e Argila & & $\mathrm{gcm}^{-3}$ & & $\mathrm{CC}$ & PMP & & VIB \\
\hline 26 & 27 & 47 & & 1,21 & & 0,28 & 0,17 & & $30 \mathrm{~mm} \mathrm{~h}^{-1}$ \\
\hline
\end{tabular}

A capacidade de infiltração de água no solo foi determinada pelo método dos anéis concêntricos, obtendo-se a velocidade básica de infiltração de 30,0 $\mathrm{mm} \mathrm{h}^{-1}$, conforme modelo de Kostiakov, de acordo com a Equação 1:

$\mathrm{I}=11,68 \times \mathrm{T}^{0,4257}$

em que:

$\mathrm{I}=$ infiltração acumulada ( $\mathrm{mm}) \mathrm{e}$

$\mathrm{T}=$ tempo acumulado (minutos).

Após o preparo do solo com uma aração (arado de três discos de 28") e duas gradagens (grade de 20 discos de 18”), a aveia preta foi semeada. O espaçamento entrelinhas foi de $0,6 \mathrm{~m}$, e a taxa de semeadura foi de 115 sementes por metro linear, misturadas a $300 \mathrm{~kg} \mathrm{ha}^{-1}$ de fertilizante NPK, na fórmula 4-14-8. A semeadura ocorreu em 04/05/92, enquanto o cultivo e a adubação de cobertura com nitrogênio, em 10/06/92, com o primeiro corte em $09 / 07 / 92$, com posterior cultivo adubação $^{-1} \mathrm{em}$ 16/07/92 e o segundo corte em 26/08/92.

A unidade experimental era composta de sete linhas de $6 \mathrm{~m}$ de comprimento, com área total de 25,2 $\mathrm{m}^{2}$, sendo consideradas, para corte e amostragem, as cinco linhas centrais, com $5 \mathrm{~m}$ de comprimento, resultando em uma área útil de $15 \mathrm{~m}^{2}$.

O método de irrigação foi a aspersão no sistema portátil convencional, operando com uma intensidade de precipitação de $13,3 \mathrm{~mm} \mathrm{~h}^{-1}$. Com base nos atributos físicos do solo, determinou-se a disponibilidade de água, em função do estádio de crescimento da aveia, usando-se a Equação 2:

$$
D R A=\frac{U c c-U p m p}{10} \times D g \times Z e x f
$$

em que: 
DRA = Disponibilidade Real de Água (mm);

Dg = Densidade Global $\left(\mathrm{g} \mathrm{cm}^{3-1}\right)$;

Ucc = Umidade na Capacidade de Campo (\%);

$\mathrm{Ze}=$ Profundidade Efetiva do Sistema Radicular $(\mathrm{cm})$;

Upmp = Umidade no Ponto de Murcha Permanente (\%);

$\mathrm{f}=$ Fator de Disponibilidade $(\mathrm{f}=0,6)$.

Considerando o consumo de água pela cultura, a irrigação foi conduzida, utilizando-se de coeficientes de cultura, para os diferentes estádios de crescimento da planta e de turnos de rega pré-determinados (Tabela 2). Desta forma, a umidade crítica calculada foi de $21,4 \%$ e os turnos de rega de 6 a 8 dias, com lâminas de 12 a $36 \mathrm{~mm}$, conforme lâmina de irrigação sugerida por Cóser e Gardner (1981).

Tabela 2. Parâmetros relacionados ao processo de irrigação da aveia preta.

\begin{tabular}{lcccccc}
\hline $\begin{array}{l}\text { Estádio de } \\
\text { crescimento }\end{array}$ & $\begin{array}{c}\text { Período } \\
\text { (dias) }\end{array}$ & $\mathrm{Ze}^{\ddagger}(\mathrm{cm})$ & $\begin{array}{c}\mathrm{DRA}^{\uparrow} \\
(\mathrm{mm})\end{array}$ & $\mathrm{Kc}^{\dagger}$ & $\begin{array}{c}\mathrm{ETm}^{*}\left(\mathrm{~mm}^{\mathrm{T}}\right. \\
\left.\mathrm{dia}^{-1}\right)\end{array}$ & $\mathrm{TR}^{\#}$ (dia) \\
\hline I & $0-15$ & $0-15$ & 12,0 & 0,5 & 2,0 & 6 \\
II & $16-35$ & 30 & 24,0 & 0,8 & 3,2 & 7 \\
III & $35-60$ & 40 & 36,0 & 1,0 & 4,0 & 8 \\
\hline
\end{tabular}

"Profundidade Efetiva do Sistema Radicular (cm); 'Disponibilidade Real de Água (mm); ${ }^{\dagger}$ Constante de Cultura; "Evapotranspiração Máxima; " Turno de Rega (TI - Turn of Irrigation).

O acompanhamento da umidade do solo foi realizado diariamente pelo método gravimétrico, sendo retiradas oito amostras (uma em cada bloco (4) em duas profundidades - 0-20 e 20-40 cm). Com os dados climáticos, possibilitou-se elaborar o balanço hídrico climatológico (Thornthwaite e Matther, 1955), representado na Figura 1. Observase ocorrência de deficiência hídrica em Pirassununga, Estado de São Paulo, no ano de 1992, alcançando 93,2 mm, distribuídos pelos meses de abril a agosto.

A fonte nitrogenada foi o sulfato de amônio, aplicado manualmente nas parcelas experimentais, sendo metade da dose aos 35 dias, e o restante, após o primeiro corte, juntamente com o cultivo. Os cortes, na área experimental, foram manuais, a uma altura de $7 \mathrm{~cm}$ do solo, sendo o $1^{\circ}$, aos 60 dias após o plantio, e o $2^{\circ}$, aos 49 dias após o $1^{\circ}$ corte.

As variáveis avaliadas associadas aos aspectos fisiológicos da planta foram: altura de planta, produção de massa seca (PMS) e taxa de crescimento da massa seca. A massa seca foi determinada pela secagem em estufa a $65-70^{\circ} \mathrm{C}$, durante 72 horas, de uma amostra da aveia recém-cortada (AOAC, 1970). $O$ delineamento experimental adotado foi o de blocos completos e casualizados, com quatro repetições, com os tratamentos dispostos em esquema de parcela subdividida em dois fatores: A) irrigação, com dois níveis, ou seja, com e sem irrigação; e B) adubação nitrogenada de cobertura e primeiro corte, com quatro doses: $\mathrm{N}_{0}=$ testemunha; $\mathrm{N}_{1}=50 \mathrm{~kg} \mathrm{~N} \mathrm{ha}{ }^{-1} ; \mathrm{N}_{2}=100 \mathrm{~kg} \mathrm{~N} \mathrm{ha}^{-1}$ e $\mathrm{N}_{3}=150 \mathrm{~kg} \mathrm{~N} \mathrm{ha}^{-1}$. Os dados foram analisados pelo programa estatístico SAS (1998).

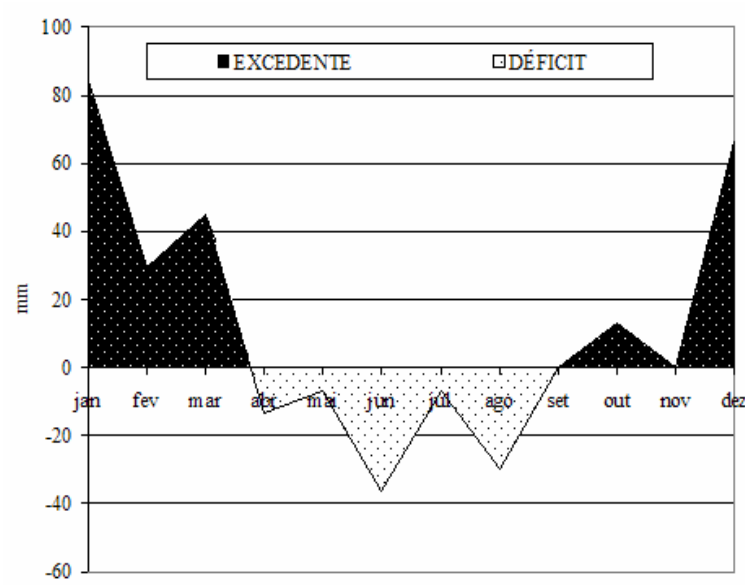

Figura 1. Balanço hídrico climatológico. Pirassununga - 1992.

\section{Resultados e discussão}

Os dados de umidade do solo encontram-se na Figura 2. Observa-se, na condição de sequeiro, restrições hídricas para o crescimento da aveia preta. A umidade do solo, nas camadas de 0 a 20 e de 20 a $40 \mathrm{~cm}$, ficou abaixo do limite crítico, respectivamente no período de 10/06 a 09/07 e a partir do dia 25/06.

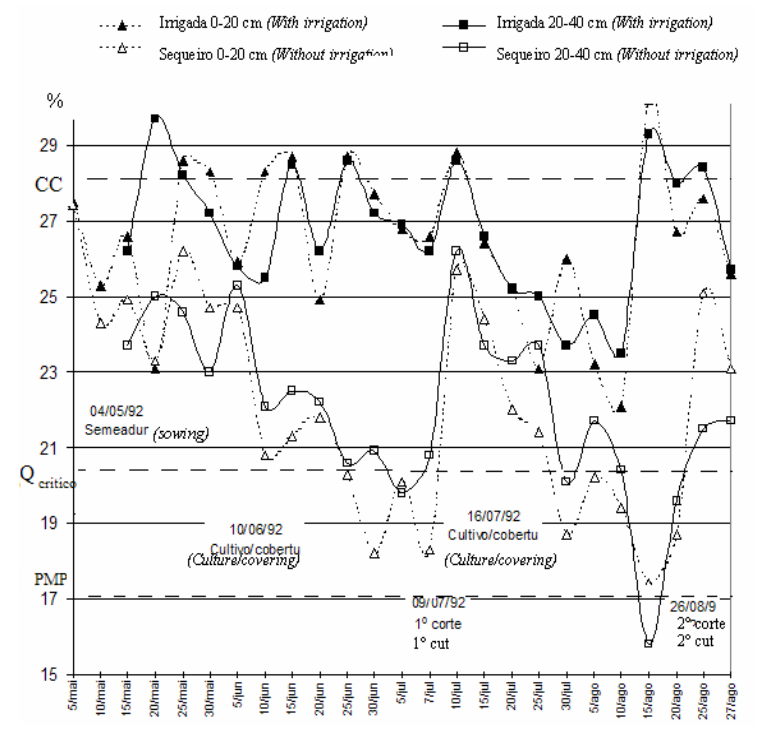

Figura 2. Umidade do solo no período de desenvolvimento da aveia preta, sob condição irrigada e de sequeiro.

Entre o $1^{\circ}$ e $\mathrm{o} 2^{\mathrm{o}}$ corte, também foram 
constatadas restrições hídricas, no entanto percebeuse que, logo após o $1^{\text {o }}$ corte, a umidade do solo, por um período de 20 dias, esteve acima do limite crítico, possibilitando condições favoráveis à rebrotação. Por outro lado, na condição irrigada, a umidade do solo sempre esteve acima do limite crítico, e na maioria dos dias (57\%), foi semelhante à umidade da capacidade de campo, caracterizando condições hídricas ótimas para o desenvolvimento da aveia preta.

Os teores de matéria seca da aveia preta foram menores na área irrigada (Tabela 3), em virtude das maiores produções, enquanto que, nas de sequeiro, os valores foram superiores, decorrentes do reduzido desenvolvimento vegetativo, conduzindo à baixa produção de forragem de alta fibra, de acordo com os comentários feitos por Teodoro (1991), embora os valores médios obtidos pelo autor estivessem abaixo dos alcançados neste estudo. Notou-se, também, aumento nos teores de matéria seca do $1^{\text {음 }}$ ao $2^{\circ}$ corte, independente do fator água.

Tabela 3. Teor de matéria seca (\%) da aveia preta ${ }^{1}$.

\begin{tabular}{|c|c|c|c|c|c|c|}
\hline \multirow[t]{2}{*}{ Irrigação } & \multirow[t]{2}{*}{ Corte } & \multicolumn{4}{|c|}{ Doses de nitrogênio - $\mathrm{kg} \mathrm{ha}^{-1}$} & \multirow[b]{2}{*}{ Média } \\
\hline & & 0 & 50 & 100 & 150 & \\
\hline Sem irrigação & $1^{\circ}$ & 22,0 & 22,3 & 22,4 & 21,4 & $22,0 \mathrm{~b}$ \\
\hline \multirow{5}{*}{ Com irrigação } & $2^{\mathrm{o}}$ & 27,9 & 27,4 & 26,6 & 27,8 & $27,4 \mathrm{a}$ \\
\hline & Média & 25,0 & 24,9 & 24,5 & 24,6 & $24,7 \mathrm{~A}$ \\
\hline & $1^{\mathrm{o}}$ & 16,7 & 17,0 & 16,3 & 16,3 & $16,6 b$ \\
\hline & $2^{\mathrm{o}}$ & 21,5 & 19,6 & 20,7 & 21,0 & $20,7 \mathrm{a}$ \\
\hline & Média & 19,1 & 18,3 & 18,5 & 18,7 & $18,7 \mathrm{~B}$ \\
\hline Média & Geral & 22,1 & 21,6 & 21,5 & 21,7 & 21,7 \\
\hline
\end{tabular}

${ }^{1}$ Médias seguidas de mesma letra maiúscula/minúscula na coluna, não diferem entre si pelo teste F (5\%)

Quanto à produção de massa seca (Tabela 4), não foi encontrada resposta significativa para as doses de $\mathrm{N}$ testadas, mas, sim, para a irrigação, estando de acordo com os dados de Teodoro (1991), que registrou a produção máxima para irrigação equivalente a $103 \%$ da evaporação do tanque classe "A", e discordando quanto à resposta à adubação nitrogenada, que o autor observou efeito quadrático, sendo obtida a produção máxima na dose de $1.57 \mathrm{~kg}$ de $\mathrm{N} \mathrm{ha}^{-1}$. É interessante ressaltar que, no referido trabalho, a testemunha do fator irrigação apresentou produção de MS semelhante $(p>0,05)$ nas doses de nitrogênio. De qualquer forma, no presente estudo, ficou evidente que a aveia preta apresentou melhor resposta à irrigação do que à adubação nitrogenada, levando-se em conta a grande deficiência hídrica ocorrida nesse ano, em Pirassununga, Estado de São Paulo (Figura 1).

Os valores de produção de massa seca, para a condição irrigada, foram semelhantes aos obtidos por Ferreira (1988), que estudou a evapotranspiração da cultura em lisímetros, alcançando produção média de $3.776 \mathrm{~kg} \mathrm{ha}^{-1}$ e máxima para o tratamento de $60 \%$ da evapotranspiração do tanque classe "A" com 3.993 $\mathrm{kg} \mathrm{ha}^{-1}$.

Tabela 4. Produção de massa seca $\left(\mathrm{kg} \mathrm{ha}^{-1}\right)$ da aveia preta ${ }^{1}$.

\begin{tabular}{lcccccc}
\hline Irrigação & Corte & \multicolumn{7}{c}{ Doses de nitrogênio $-\mathrm{kg} \mathrm{ha}^{-1}$} \\
\hline Sem irrigação & & 0 & 50 & 100 & 150 & Média \\
& $1^{\mathrm{o}}$ & 641 & 735 & 688 & 675 & $683 \mathrm{a}$ \\
& $2^{\mathrm{o}}$ & 790 & 731 & 749 & 781 & $764 \mathrm{a}$ \\
& Total & 1431 & 1466 & 1437 & 1456 & 1447 \\
\cline { 2 - 7 } Com irrigação & Média & 716 & 733 & 719 & 728 & $723 \mathrm{~B}$ \\
\cline { 2 - 7 } & $1^{\circ}$ & 2582 & 2782 & 2954 & 2885 & $2828 \mathrm{a}$ \\
& $2^{\mathrm{o}}$ & 925 & 824 & 672 & 620 & $761 \mathrm{~b}$ \\
& Total & 3507 & 3606 & 3626 & 3505 & 3589 \\
\cline { 2 - 7 } & Média & 1766 & 1802 & 1832 & 1766 & $1781 \mathrm{~A}$ \\
\hline Média & Geral & 1241 & 1268 & 1276 & 1247 & 1252 \\
\hline
\end{tabular}

${ }^{1}$ Médias seguidas de mesma letra maiúscula/minúscula na coluna não diferem entre si pelo teste $\mathrm{F}(5 \%)$

No estudo conduzido por Reis et al. (1993a), foi obtido, para a aveia preta, produção de massa seca de $1.751 \mathrm{~kg} \mathrm{ha}^{-1}$ para o corte aos 60 dias, numa condição irrigada, ficando abaixo da média encontrada, nesse experimento, para o mesmo período de dias. Todavia, aos 74 dias, aqueles autores encontraram produção de $3.983 \mathrm{~kg} \mathrm{MS} \mathrm{ha}{ }^{-1}$, ficando acima do valor obtido de $2.828 \mathrm{~kg} \mathrm{MS} \mathrm{ha}{ }^{-1}$, conforme pode ser visto na Tabela 4. Para a rebrotação, os referidos autores usaram o período de 60 dias, obtendo maiores produções de massa seca, da ordem de 4.848 $\mathrm{kg} \mathrm{ha}^{-1}$, chegando a alcançar o estádio de produção de grãos leitosos, enquanto que, no presente estudo, o período foi de 49 dias, levando a produções menores. Dando seqüência ao estudo com aveia, Reis et al. (1993b) testaram cultivares de aveia (preta e amarela) em diferentes épocas de plantio, encontrando respostas favoráveis ao plantio precoce (início de abril), obtendo $5.747 \mathrm{~kg} \mathrm{MS} \mathrm{ha}{ }^{-1}$ contra 3.463 da última época. Os autores verificaram que o desempenho do plantio tardio foi comprometido pela elevação da temperatura e duração do dia, após primeiro corte, induzindo a planta ao florescimento. No estudo de Alvim et al. (1994), as produções de massa seca também seguiram mesmo comportamento, sendo superior para o plantio mais precoce. Os dados de produção de $\mathrm{MS} \mathrm{ha} \mathrm{ha}^{-1}$ foram de $853 \mathrm{~kg} \mathrm{ha}^{-1}$ no $1^{\mathrm{o}}$ corte da aveia em sequeiro e de $1.878 \mathrm{~kg} \mathrm{ha}^{-1}$ em irrigação, com freqüência de sete dias, semelhantes aos obtidos neste estudo, todavia, foram realizados três cortes da aveia, o que gerou produção mais elevada.

Quanto à adubação nitrogenada, Alvim et al. (1987) encontraram efeitos positivos para a dose de $100 \mathrm{~kg} \mathrm{ha}^{-1}$, num intervalo testado de 0 a $400 \mathrm{~kg} \mathrm{ha}^{-1}$, após três cortes realizados, com produções semelhantes às obtidas nesse estudo. Cabe comentar que, embora não tenha obtido efeitos significativos, a dose de $100 \mathrm{~kg}$ de $\mathrm{N} \mathrm{ha}^{-1}$ favoreceu a obtenção de 
maior produção de massa seca. Os dados de altura de planta são apresentados na Tabela 5, na qual são observadas respostas significativas e positivas para a irrigação. Essa variável evidenciou o efeito significativo da adubação nitrogenada em irrigação, obtendo-se por meio da análise de regressão, ajuste linear para as doses de nitrogênio testadas na altura das plantas. A equação de regressão, para a altura em função das doses de $\mathrm{N}$ na área irrigada, foi $\hat{\mathrm{y}}=62,3$ $+0,0417 \mathrm{x}(\mathrm{r}=0,84)$. Cabe comentar que, no estudo de Teodoro (1991), três doses de $\mathrm{N}$ foram testadas, atingindo até $240 \mathrm{~kg}$ de $\mathrm{N} \mathrm{ha}^{-1}$, enquanto que, na presente pesquisa, adotaram-se dosagens de até 150 $\mathrm{kg}$ de $\mathrm{N} \mathrm{ha}^{-1}$.

$\mathrm{Na}$ área de sequeiro, a altura da planta foi diferente $(\mathrm{p}<0,05)$ nos dois cortes, sendo maiores médias no $2^{\circ}$ corte, o que pode ser explicado pela umidade favorável ao desenvolvimento da aveia preta encontrada no solo logo após o 1ำ corte (Figura 2). Os dados do experimento não diferiram da faixa de altura sugerida por Pereira (1988), situada entre 50 e $60 \mathrm{~cm}$ para o corte, o que se verificou na condição irrigada. Em condição de lisímetro, Ferreira (1988) registrou a altura de $60 \mathrm{~cm}$ para a aveia preta cortada aos 53 dias.

Tabela 5. Alturas médias $(\mathrm{cm})$ de planta de aveia preta ${ }^{1}$.

\begin{tabular}{lcccccc}
\hline Irrigação & Corte & \multicolumn{7}{c}{ Doses de nitrogênio $-\mathrm{kg} \mathrm{ha}^{-1}$} & \\
\hline \multirow{4}{*}{ Sem irrigação } & & 0 & 50 & 100 & 150 & Média \\
& $1^{\mathrm{o}}$ & 37,9 & 36,7 & 37,1 & 39,2 & $37,7 \mathrm{~b}$ \\
& $2^{\mathrm{o}}$ & 49,8 & 53,3 & 52,1 & 56,4 & $52,9 \mathrm{a}$ \\
\cline { 2 - 7 } Com irrigação & Média & 43,9 & 45,0 & 44,6 & 47,8 & $45,3 \mathrm{~B}$ \\
\cline { 2 - 7 } & $1^{\mathrm{o}}$ & 71,0 & 68,3 & 78,3 & 80,2 & $74,4 \mathrm{a}$ \\
& $2^{-}$ & 55,1 & 56,2 & 58,5 & 55,7 & $56,4 \mathrm{~b}$ \\
\cline { 2 - 7 } & Média & $63,1 \mathrm{~b}$ & $62,3 \mathrm{~b}$ & $68,4 \mathrm{a}$ & $68,0 \mathrm{a}$ & $65,4 \mathrm{~A}$ \\
\hline Média & Geral & $53,5 \mathrm{~b}$ & $53,7 \mathrm{~b}$ & $56,5 \mathrm{ab}$ & $57,9 \mathrm{a}$ & 55,4 \\
\hline
\end{tabular}

${ }^{1}$ Médias seguidas de mesma letra maiúscula/minúscula na coluna, não diferem entre si pelo teste $\mathrm{F}(5 \%)$

Tabela 6. Taxa de crescimento ( $\mathrm{kg} \mathrm{MS}$ ha dia $\left.{ }^{-1}\right)$ da aveia preta ${ }^{1}$.

\begin{tabular}{|c|c|c|c|c|c|c|}
\hline \multirow[t]{2}{*}{ Irrigação } & \multirow[t]{2}{*}{ Corte } & \multicolumn{4}{|c|}{ Doses de nitrogênio - $\mathrm{kg} \mathrm{ha}^{-1}$} & \multirow[t]{2}{*}{ Média } \\
\hline & & 0 & 50 & 100 & 150 & \\
\hline Sem irrigação & $1^{\circ}$ & 10,7 & 12,3 & 11,5 & 11,3 & $11,4 \mathrm{~b}$ \\
\hline \multirow{5}{*}{ Com irrigação } & $2^{\underline{\mathrm{o}}}$ & 16,1 & 14,9 & 15,3 & 15,9 & $15,6 \mathrm{a}$ \\
\hline & Média & 13,4 & 13,6 & 13,4 & 13,6 & $13,5 \mathrm{~B}$ \\
\hline & $1^{\circ}$ & 43,3 & 46,6 & 49,7 & 48,5 & $47,1 \mathrm{a}$ \\
\hline & $2^{\underline{o}}$ & 19,0 & 16,5 & 13,9 & 12,7 & $15,5 b$ \\
\hline & Média & 31,2 & 31,6 & 31,8 & 30,6 & $31,3 \mathrm{~A}$ \\
\hline Média & Geral & 22,3 & 22,6 & 22,6 & 22,1 & 22,4 \\
\hline
\end{tabular}

${ }^{1}$ Médias seguidas de mesma letra maiúscula/minúscula na coluna, não diferem entre si pelo teste $\mathrm{F}(5 \%)$.

Pela análise estatística, observou-se resposta para a irrigação e diferentes taxas de crescimento entre o $1^{\circ}$ e $2^{\circ}$ cortes, em ambas as condições (Tabela 6). Quanto ao fator irrigação, no entanto, nota-se que, na área irrigada, ocorreu redução da taxa de crescimento do $1^{\mathrm{o}}$ ao $2^{\mathrm{o}}$ corte, enquanto que, na área de sequeiro, houve aumento. Tal comportamento pode ser explicado pelas condições hídricas do solo logo após o $1^{\circ}$ corte que favoreceu a rebrota e gerou taxas de crescimento semelhantes à da condição irrigada. Além desse aspecto, houve acréscimo significativo da porcentagem de matéria seca no $2^{\text {o }}$ corte, aliado ao menor período de tempo para a obtenção da produção de massa seca.

\section{Conclusão}

Desse modo, conclui-se que o cultivo de outono inverno $^{-1}$ da aveia preta, na região de Pirassununga, Estado de São Paulo, requer o uso da irrigação. A adubação nitrogenada não exerceu influência na produção de massa seca, apesar de a altura das plantas ter apresentado o efeito quadrático em função das doses de nitrogênio.

\section{Referências}

ALVIM, M.J. et al. Efeito da fertilização nitrogenada sobre a produção de matéria seca e teor de proteína bruta da aveia (Avena sativa L.), na Zona da Mata de Minas Gerais. In: REUNIÃO ANUAL DA SOCIEDADE BRASILEIRA DE ZOOTECNIA, 24., 1987, Brasília, Anais... Brasília: SBZ, 1987. p. 171.

ALVIM, M.J. et al. Efeito da época de plantio e da freqüência da irrigação em aveia sobre a produção de matéria seca e teor de proteína bruta. Rev. Soc. Bras. Zootec., Viçosa, v. 23, n. 1, p. 47-56, 1994.

AOAC-Association of Official Agricultural Chemists. Official methods of analysis. 12. ed. Washington, D.C.: AOAC, 1970.

CÓSER, L.A.; GARDNER, A.L. Desempenho de animais sob pastejo contínuo. Coronel Pacheco: Embrapa/CNPGL, 1981.

FERREIRA, E.J. Determinação da evapotranspiração $e$ do coeficiente de cultura (Kc) para a aveia preta (Avena strigosa, Schreb). 1988. Dissertação (Mestrado)-Universidade Federal de Viçosa, Viçosa, 1988.

FLARESSO, J.A.; ALMEIDA, E.X. Introdução e avaliação de forrageiras temperadas no Alto Vale do Itajaí, Santa Catarina. Rev. Soc. Bras. Zootec., Viçosa, v. 21, n. 2, p. 309319, 1992.

FLOSS, E.L. Manejo forrageiro da aveia (Avena ssp) e azevém (Lolium spp). I $n$ : SIMPÓSIO SOBRE MANEJO DE PASTAGENS, 9., 1988, Piracicaba. Anais... Piracicaba: Fealq, 1988, p. 231-268.

GODOY, R.S. et al. Caracterização de cultivares de aveia forrageira em São Carlos-SP. São Carlos: Embrapa: UEPAE, 1990. (Comunicado técnico, 4).

PEREIRA, P.J. Forrageiras de inverno. Inf. Agropecu., Belo Horizonte, v. 13, n. 53, p. 54-62, 1988.

REIS, R.A. et al. Produção e qualidade da forragem de aveia (Avena spp.). Rev. Soc. Bras. Zootec., Viçosa, v. 22, n. 1, p. 99-109, 1993 a.

REIS, R.A. et al. Rendimento e qualidade da forragem de 
genótipos de aveia semeados em diferentes épocas. Rev. Soc. Bras. Zootec., Viçosa, v. 22, n. 4, p. 642-650, 1993 b.

SAS-Statistical Analysis System. SAS user's guide: release 6.03. Cary: SAS Institute, 1998.

TEODORO, R.E.F. Efeitos da irrigação e adubação nitrogenada na produção de forragens e grãos de aveia (Avena sativa L.). 1991. Tese (Doutorado) - Escola Superior de Agricultura "Luiz de Queiroz", Universidade de São
Paulo, Piracicaba, 1991.

THORNTHWAITE, C.W.; MATTHER, J.R. The water balance. Centerton: Drexel Institute of Technology, 1955. (Publications in Climatology, v. 8, n. 1).

Received on February 28, 2007.

Accepted on August 07, 2007. 